\title{
Social influence on avoidance of dangerous stimuli by rats
}

\author{
DAVID J. WHITE and BENNETT G. GALEF, JR. \\ McMaster University, Hamilton, Ontario, Canada
}

\begin{abstract}
Three experiments were conducted to determine whether a naive observer rat would avoid contact with a shock prod after watching a demonstrator rat contact, be shocked by, and defensively bury the prod. We found that observer rats took longer to contact prods that had delivered a shock to and been buried by a demonstrator rat than to contact prods that had not delivered shock and had not been buried. However, observer rats contacted prods buried by an unseen demonstrator rat or by an unseen experimenter with the same latencies as those for prods they had seen deliver shock to and be buried by a demonstrator rat. In large enclosures, subjects took $1-2 \mathrm{~h}$ longer to contact buried prods than to contact unburied prods. We conclude that alteration of the physical environment by individuals receiving noxious stimulation can significantly reduce the probability that conspecifics will contact the noxious stimulus. Observational learning per se, however, need not be involved.
\end{abstract}

Naive Norway rats (Rattus norvegicus) can learn from knowledgeable conspecifics what foods to eat and both where and when food is available (Galef, 1996; Galef \& White, 1997). Rats also learn socially to kill mice (Flandera \& Novakova, 1973), to recover seeds from pine cones efficiently (Terkel, 1996), and to perform simple motor acts to produce food (Heyes, 1996).

Surprisingly, although such social facilitation of the acquisition of appetitive responses has been demonstrated repeatedly in Norway rats, and socially learned avoidance of potentially dangerous objects has been demonstrated many times in vertebrate species other than rats (Curio, 1988; Mason, 1988; Mineka \& Cook, 1988), rats have not been shown to learn avoidances socially (Galef, McQuoid, \& Whiskin, 1990; Galef, Wigmore, \& Kennett, 1983).

The sole possible example of social learning of an avoidance by rats of which we are aware is an unconvincing report published in 1971 by Lore, Blanc, and Suedfeld. Lore et al. found that rats that observed conspecific demonstrators learn to avoid making contact with candle flames stopped putting their noses into similar flames more rapidly than did control subjects that had not observed others learn to avoid flames. However, as Lore et al. acknowledged in discussion of their results, the experimental design did not exclude the possibility that these subjects were simply sensitized to noxious stimuli by exposure to the sounds or odors emitted by singed conspecifics.

In the present experiment, we made use of the tendency of rats to bury localized sources of aversive stimulation

This research was supported by a grant from the Natural Sciences and Engineering Research Council of Canada to B.G.G. Correspondence concerning this article should be addressed to B. G. Galef, Jr., Department of Psychology, McMaster University, Hamilton, ON, L8S 4K1 Canada (e-mail: galef@mcmaster.ca).
(Pinel \& Treit, 1978) in order to look for evidence of social learning of avoidance in Norway rats. Such defensive burying directed toward noxious stimuli has been demonstrated in a variety of laboratory situations (Heynen, Sainsbury, \& Montoya, 1989; Pinel, Treit, \& Wilkie, 1980) and is, presumably, a laboratory analogue of burying behaviors that members of several rodent species have been observed to direct toward potentially dangerous objects in natural circumstances (Owings \& Coss, 1977).

In Experiment 1 of the present series, we demonstrated that Norway rats increased their latencies to contact potentially noxious objects after observing conspecifics contact such objects, receive noxious stimulation, and respond by burying the objects. In Experiment 2, we analyzed the causes of such socially mediated avoidance, and in Experiment 3, we examined its potential importance in a more natural setting.

\section{EXPERIMENT 1}

We undertook Experiment 1 to look for evidence that Norway rats might learn to avoid contact with a noxious object by observing the response of a conspecific to that object. We first allowed naive observer rats to see a demonstrator rat be shocked by, and then bury, one of two similar, but discriminable prods. We then measured each observer's latencies to contact both noxious and inactive prods.

\section{Method}

\section{Subjects}

Twenty-two 50-day-old female Long-Evans rats acquired from the Central Animal Facility of the McMaster University Medical Centre, which had served previously as subjects in an experiment on social influences on food choice, served as subjects in the present experiment. We randomly assigned the 22 animals to pairs and then randomly assigned one member of each pair to act as the demonstrator and the other to act as the observer in that pair. 


\section{Apparatus}

The experiment took place in a test enclosure, measuring $48 \times$ $30.5 \times 30.5 \mathrm{~cm}$, that we constructed of transparent Plexiglas (Figure $1 \mathrm{~A}$ ). We used a removable, transparent Plexiglas partition to create two compartments, one of which, the demonstrator's compartment, measured $30 \times 30.5 \times 30.5 \mathrm{~cm}$, and the other of which, the observer's compartment, measured $18 \times 30.5 \times 30.5 \mathrm{~cm}$. The test enclosure had no floor, but instead rested on a tray covered to a depth of $3 \mathrm{~cm}$ with wood chips (Beta Chips, Northeast Products Corp., Warrensberg, NY).

We drilled a 1-cm-diameter hole at the midpoint and $5 \mathrm{~cm}$ above the bottom edge of both the front and back walls of the demonstrator's compartment. When the experiment required, we inserted two pieces of balsa-wood dowel $.75 \mathrm{~cm}$ in diameter, one painted white and the other black, through these holes and $3 \mathrm{~cm}$ into the demonstrator's compartment. Both pieces of dowel were wrapped with two uninsulated wires to make potential shock prods, and either prod could be connected to a $600-\mathrm{V}, 5-\mathrm{mA}$ shock source, as the experiment required.

\section{Procedure}

Habituation. Before starting the experiment proper, we familiarized both demonstrators and observers with the test enclosure by placing them alone in the apparatus for $20 \mathrm{~min}$ on each of $3 \mathrm{con}$ secutive days, with the partition separating the demonstrator's and observer's compartments removed and no prods inserted in the holes in the front and back walls of the demonstrator's compartment.

Testing. To begin the experiment, we inserted the two prods into the openings in the demonstrator's compartment and connected one of them (the active prod) to the shock source, counterbalancing across subjects both the color and the location of the active prod.

We then replaced the partition separating the demonstrator's and observer's compartments, placed the observer in its compartment, waited $2 \mathrm{~min}$ for the observer to settle down, and then placed the demonstrator in her compartment.

We then waited until the demonstrator placed her paw on the active prod, and delivered a shock via the prod that lasted until the demonstrator pulled her paw from it (approximately $42.9 \mathrm{msec}$; Pinel \& Treit, 1978).

We then (1) turned off the shock generator, (2) left the demonstrator undisturbed for $10 \mathrm{~min},(3)$ removed from the apparatus both the demonstrator and the partition separating the demonstrator's compartment from that housing the observer, (4) recorded the observer's latency to contact both the active and inactive prods for the first time, and (5) recorded the time that the observer spent either in contact with or sniffing at each prod during the next $10 \mathrm{~min}$.

Behavior of both demonstrator and observer was observed with the use of a closed-circuit television camera (Panasonic WV-CL110) and color monitor (CT-1331) and recorded on videotape (Panasonic AG-1240) along with the display from a time-date generator (Panasonic WJ-810) that allowed subsequent determination of latencies to contact prods and durations of contact with prods.

\section{Results and Discussion}

All 11 demonstrators made contact with both active and inactive prods within 10 min of their introduction into the test enclosure. Contact with the active $\operatorname{prod}(M \pm$
A:

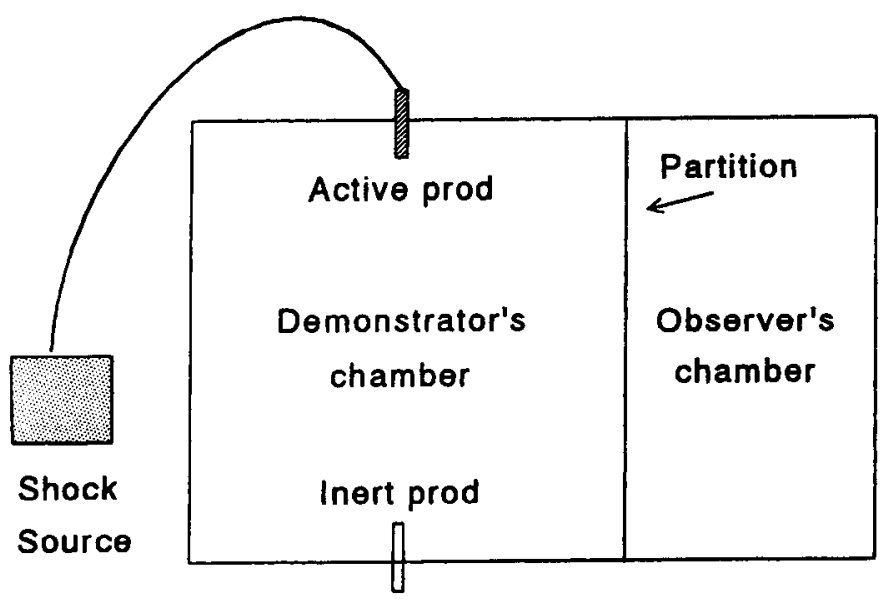

$0.5 \mathrm{~m}$
B: Water bottles
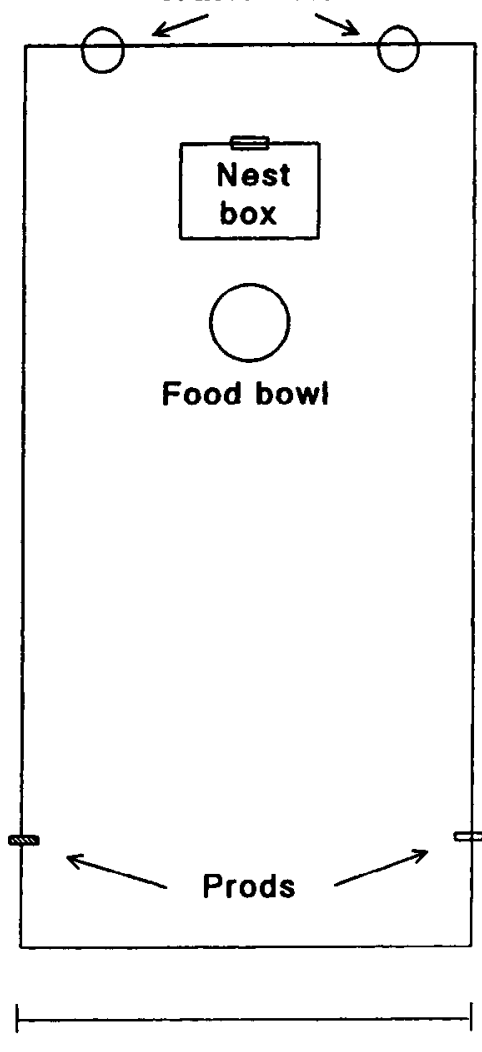

$1 \mathrm{~m}$

Figure 1. Overhead schematic drawings of apparatus used in (A) Experiments 1 and 2 and (B) Experiment 3. 
$S E M=5.05 \pm .73 \mathrm{~min}$ ), resulting in a brief but intense shock's being delivered to a demonstrator's forepaw, caused the demonstrator to withdraw its forepaw from the active prod, to give a startle response, sometimes to vocalize, and often to remain immobile for a few seconds. Within 1 min after receiving a shock, 10 of the 11 demonstrators began to engage in defensive burying, spending an average $( \pm 1 S E M)$ of $3.20 \pm 1.01$ min using its snout and forepaws to pile wood chips on the active prod, and, in every case, completely burying it. No demonstrator directed any burying behavior toward the inactive prod.

The observers did not appear to attend closely to the activities of their respective demonstrators either when the demonstrator was shocked or while the demonstrator engaged in defensive burying of the active prod. Observers often spent much of the time while they and their demonstrators were in the test enclosure grooming or lying unmoving on the enclosure floor.

After we removed the demonstrators from the test enclosure, 9 of the 10 observers that saw their respective demonstrators engage in defensive burying made contact with the inactive prod (mean latency $\pm S E M=.44 \pm$ $.11 \mathrm{~min}$ ) before they made contact with the active prod $[2.82 \pm .79 \mathrm{~min}$; sign test, $x(9)=1, p<.03]$, and each observer's latency to contact its inactive prod averaged $2.38 \pm$ $.71 \mathrm{~min}$ less than its latency to contact its active prod [matched $t$ test, $t(9)=3.35, p<.01$ ] . Observers spent equal time investigating active $(1.60 \pm .71 \mathrm{~min})$ and inactive $(1.88 \pm .68 \mathrm{~min})$ prods $[t(9)=.24, \mathrm{n} . \mathrm{s}$.$] , and no observer$ pushed wood chips toward either prod while it was in the apparatus.

As in the study of observational learning of avoidance of a candle flame described in the introduction (Lore et al., 1971), the behavior of demonstrator rats in the present experiment affected the contact of observer rats with a potentially noxious stimulus. However, also as in Lore et al.'s study, the finding that demonstrators affected their observers' behavior offers little insight into how that effect was achieved.

\section{EXPERIMENT 2}

In Experiment 1, the behavior of demonstrators might have affected the behavior of their observers in at least two quite different ways: First, observers might have learned to avoid contact with the active prod by observing their demonstrators respond to it. Alternatively, demonstrators that engaged in defensive burying of the active prod concealed it beneath a mound of wood chips, and this concealment might have been the sole cause of observers' greater latencies to contact active as opposed to inactive prods.

We undertook Experiment 2 to determine whether observation of the behavior of demonstrators or physical concealment of active prods was responsible for the significant difference in mean latencies with which observers in Experiment 1 first contacted active and inactive prods.

\begin{abstract}
Method
Subjects

We randomly assigned ninety 50-day-old female Long-Evans rats to 40 demonstrator-observer pairs, and the final 10 subjects to a fourth condition that required no demonstrators.
\end{abstract}

\section{Apparatus}

We used the same apparatus as in Experiment 1.

\section{Procedure}

Control group ( $n=11$ pairs). We treated demonstrators and observers assigned to the control group exactly as we had treated the subjects in Experiment I, except that, to control for manipulations that we administered to the other three groups in the present experiment, we placed an opaque barrier, a piece of Bristol board (measuring $30.5 \times 30.5 \mathrm{~cm}$ ), between the demonstrator's and observer's compartments while we removed the demonstrator from the test enclosure at the end of the 10-min period when the demonstrator was in the apparatus.

Uncovered group ( $n=15$ pairs). We treated the demonstrators and observers assigned to the uncovered group exactly as we treated the demonstrators and observers assigned to the control group, except that, after we placed the Bristol board between the demonstrator's and observer's compartments, we not only removed the demonstrator from the apparatus, but also used a clean wooden spoon to smooth the wood chips throughout the demonstrator's compartment. As a result of our activities, active and inactive prods were made equally accessible, and the demonstrator's compartment looked much as it did before we introduced the demonstrator into it.

Unseen group ( $n=14$ pairs). We treated demonstrators and observers assigned to the unseen group exactly as we treated demonstrators and observers in Experiment 1, except that, while the demonstrator was in her compartment, we separated the demonstrator's and observer's compartments with an opaque Bristol board partition as well as a transparent Plexiglas partition. Thus, observers assigned to the unseen group could not see their respective demonstrators responding to prods, but like observers assigned to the control group, they did encounter one prod buried by a demonstrator and one visible prod when they entered the demonstrator's compartment after the demonstrator had been removed from it.

Experimenter-buries group ( $n=10$ observers). We treated observers assigned to the experimenter-buries group as we treated subjects in the control group, except that (1) we never placed a demonstrator in the demonstrator's compartment of the test enclosure, and (2) after we placed the Bristol board partition between the demonstrator's and observer's compartments 10 min after the start of an experimental session, we completely buried a randomly selected prod under a pile of wood chips, producing a mound of wood chips as much like those produced by demonstrators that engaged in defensive burying of the active prod as we could make them.

\section{Results and Discussion}

Five of the demonstrators failed to contact the active prod within $10 \mathrm{~min}$ of being placed in the test enclosure, and 5 more demonstrators failed to exhibit defensive burying after they received a shock. We discarded data from the observers in each of these 10 pairs, leaving 10 pairs/group.

A one-way analysis of variance performed on differences in the latencies of the 40 observers to contact the inactive and active prods showed a significant effect of group assignment on latencies to contact the two prods 


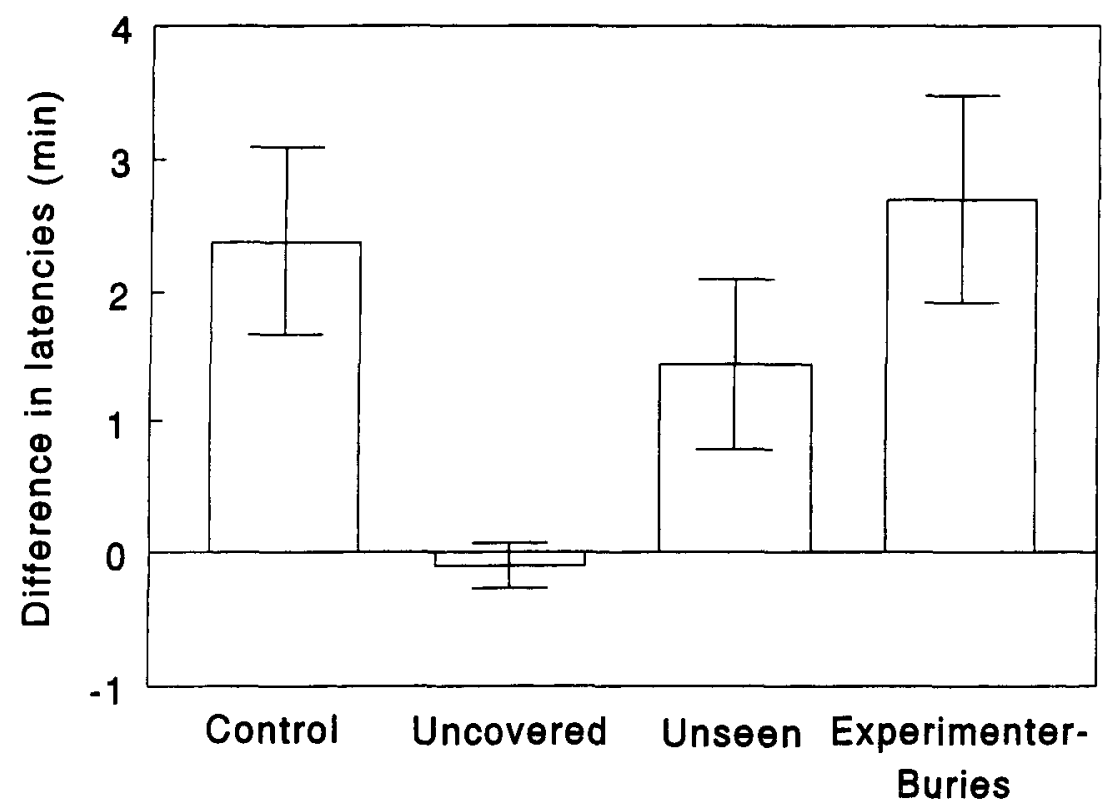

Figure 2. Mean latency, in minutes, with which each observer in Experiment 2 first made contact with the prod that was active for its demonstrator or buried by the experimenter minus that observer's latency to first make contact with the prod that was inactive for its demonstrator or unburied by the experimenter. Error bars represent $\pm 1 S E M$.

$[F(3,36)=4.06, p<.02$; Figure 2]. Tukey's multiplecomparison, post hoc tests revealed that (1) observers assigned to the control, unseen, and experimenter-buries groups did not differ from one another, and (2) latencies to contact the active prod after contacting the inactive prod of observers assigned to both control and experimenterburies groups differed significantly from those of subjects assigned to the uncovered group (both $p s<.04$ ).

The results of Experiment 2 are consistent with the view that observation of a demonstrator receiving a shock and burying an active prod was not necessary to produce the greater latencies to contact the active as opposed to the inactive prod exhibited by observers in Experiment 1. Rather, increased latencies to contact active prods can result from the physical concealment of prods caused by defensive burying, even when observers have no opportunity to see the act of concealment occur: (1) Increases in subjects' latencies to contact prods buried by either an unseen conspecific demonstrator or a human experimenter were as great as were the increases in subjects' latencies to contact prods after the subjects both saw those prods shock a demonstrator and the demonstrator bury the prod, and (2) prods that observers had seen shock a demonstrator and be buried by a demonstrator and that were then uncovered by an unseen experimenter were contacted as rapidly as were inactive prods.

\section{EXPERIMENT 3}

Although the results of both Experiments 1 and 2 indicate that a rat takes longer to contact a buried prod than a visible one, most observers made contact with the bur- ied prod in the test enclosure within 2-3 min of contacting the visible one. It is unlikely that such a small increase in latency to contact a potentially dangerous object would be of any significance in the life of an animal living in natural circumstances. However, in both Experiments 1 and 2, we confined observers in a small $\left(.15 \mathrm{~m}^{2}\right)$ test enclosure. Consequently, the probability was great that an observer would contact a prod, whether buried or visible, in the course of its random exploration of the enclosure.

In the present experiment, we confined subjects with both a buried and a visible prod in a large enclosure $\left(2 \mathrm{~m}^{2}\right)$ to determine whether, in a situation more like that experienced by free-living rats, defensive burying of a prod might have a meaningful effect on the latency with which a naive rat contacted it.

\[ \text { Method } \]
Subjects
Ten 50 -day-old female Long-Evans rats acquired from the Cen-
tral Animal Facility at the McMaster University Medical Centre
served as subjects.

\section{Apparatus}

We constructed a large cage, measuring $2.0 \times 1.0 \times .3 \mathrm{~m}$, of angle iron, galvanized sheet metal, and hardware cloth, and covered the floor of the enclosure to a depth of $3 \mathrm{~cm}$ with the same wood-chip bedding that we used in Experiments 1 and 2. As can be seen in Figure 1B, we placed a nest box, food bowl, and water bottles in the enclosure so that it was suitable for long-term occupation by our subjects, and, at an appropriate time (see Procedure below), we inserted the same two prods that we had used in Experiments 1 and 2 in opposite walls of the cage, $5 \mathrm{~cm}$ above its floor and $25 \mathrm{~cm}$ from the end distant from the nest box.

The room containing the experimental apparatus was permanently illuminated with a $40-\mathrm{W}$ red bulb that provided sufficient 
light to permit video recording. The far brighter overhead fluorescent lights were illuminated on a 12:12-h light:dark cycle, with light onset at 8 a.m.

A closed-circuit television camera (Panasonic WV-CL110), mounted above the enclosure and attached to a time-lapse video recorder with internal time-date generator (Panasonic AG-6730), allowed us to monitor behavior in the enclosure $24 \mathrm{~h} /$ day.

\section{Procedure}

To start the experiment, we placed a single subject in the enclosure $2 \mathrm{~h}$ after light onset, and left it undisturbed for $24 \mathrm{~h}$ to habituate to the experimental situation. At the end of the habituation period, we placed the prods in position in the walls of the enclosure and randomly chose one prod and buried it under a pile of wood chips, replicating as closely as we could the results of defensive burying by rat demonstrators in Experiments 1 and 2. We then left the subject undisturbed in the enclosure until she had contacted both prods.

\section{Results and Discussion}

Subjects contacted the visible prod before they contacted the buried prod [sign test, $x(10)=1, p<.03$ ], and they contacted the buried prod an average $( \pm 1 S E M)$ of $114.20 \pm 65.05 \mathrm{~min}$ after the visible prod. Thus, increasing the area of the enclosure in which subjects were housed 15 -fold (from .15 to $2 \mathrm{~m}^{2}$ ) increased the difference in subjects' latencies to contact buried and visible prods more than 50 -fold (from roughly 2 to $114 \mathrm{~min}$ ).

Of course, there were differences other than in the size of enclosures between the conditions of testing of subjects in Experiments 1 and 2 and 3. However, in all particulars, the conditions of Experiment 3 were more like those in which rats might live outside the laboratory than were the conditions of Experiments 1 and 2. Consequently, the results of Experiment 3 suggest that, in natural circumstances, defensive burying of an object by one rat would substantially delay other rats' contact with that object.

\section{GENERAL DISCUSSION}

The results of Experiments 1 and 2 are consistent with results of previous experiments suggesting that Norway rats do not easily acquire avoidance responses by watching conspecifics suffer the consequences of contacting sources of noxious stimulation. On the other hand, the results of Experiment 3 suggest that, in natural circumstances, a rat that has learned to avoid contact with a potentially noxious stimulus will, by burying the stimulus, substantially increase the latencies with which naive conspecifics will come into contact with it. Such alteration of the environment, resulting in biasing of the responses of others, is a common means of social influence on behavior both in rats and in other species (Galef, 1976). For example, Norway rats introduced into territories of strange rat colonies make use of the paths and burrows constructed by territory residents (Telle, 1966), and young black rats (Rattus rattus) that have opportunities to interact with pine cones that adults have started to strip of their scales learn to remove the scales from pine cones in an efficient manner (Terkel, 1996).

Possibly, given the matrilocal structure of Norway rat populations in natural circumstances (Calhoun, 1962), defensive burying of noxious stimuli by Norway rats evolved as a means of reducing the probability that close relatives would suffer injury. Alternatively, if hiding an object from view decreases the probability that the individual that concealed the object would contact it again, then defensive burying may have evolved to benefit the individual doing the burying. In this case, the increased latency with which conspecifics of a concealer contact a concealed object would be an evolutionary epiphenomenon.

There is no term in the lexicon of social learning (Galef, 1988; Whiten \& Ham, 1992) that refers to a tendency for the results of the acts of one individual to reduce the probability that conspecifics will engage in an act, and we are unwilling to create a neologism that would increment an already cumbersome nomenclature that has proved to be of limited utility (Galef, 1976).

However, labeled or not, influences on behavior of the type demonstrated here, obviously of social origin, have the potential to play an important role in the development of adaptive behavioral repertoires in animals living outside the laboratory. As the results of the present experiments make clear, the tendency of rats to bury noxious objects can reduce the probability that conspecifics will come into contact with such objects.

\section{REFERENCES}

Calmoun, J. B. (1962). The ecology and sociology of the Norway rat. Bethesda, MD: U.S. Department of Health, Education and Welfare CuRIO, E. (1988). Cultural transmission of enemy recognition by birds In T. R. Zentall \& B. G. Galef, Jr. (Eds.), Social learning: Psycholog ical and biological perspectives (pp. 75-98). Hillsdale, $\mathrm{NJ}$ : Erlbaum.

Flandera, V., \& Novakova, V. (1973). Effect of mother on the development of aggressive behavior in rats. Developmental Psychobiology, $8,49-54$

GALEF, B. G., JR. (1976). Social transmission of acquired behavior: A discussion of tradition and social learning in vertebrates. Advances in the Study of Behavior, 6, 77-100.

GALEF, B. G., JR. (1988). Imitation in animals: History, definition and interpretation of data from the psychological laboratory. In T. R. Zentall \& B. G. Galef, Jr. (Eds.), Social learning: Psychological and biological perspectives (pp. 3-28). Hillsdale, NJ: Erlbaum.

GaLEF, B. G., JR. (1996). Social enhancement of food preferences in Norway rats: A brief review. In C. M. Heyes \& B. G. Galef, Jr. (Eds.), Social learning in animals: The roots of culture (pp. 49-64). San Diego: Academic Press.

GaleF, B. G., JR., McQuoid, L. M., \& Whiskin, E. E. (1990). Further evidence that Norway rats do not socially transmit learned aversions to toxic baits. Animal Learning \& Behavior, 18, 199-205.

GALEF, B. G., JR., \& WHITE, D. J. (1997). Socially acquired information reduces rats' latencies to find food. Animal Behaviour, 54, 705-714.

Galef, B. G., JR., Wigmore, S. W., \& Kennett, D. J. (1983). A failure to find socially mediated taste-aversion learning in Norway rats (R. norvegicus). Journal of Comparative Psychology, 97, 358-363

HEYES, C. M. (1996). Genuine imitation? In C. M. Heyes \& B. G. Galef, Jr. (Eds.), Social learning in animals: The roots of culture (pp. 373390). San Diego: Academic Press.

Heynen, A. J., Sainsbury, R. S., \& Montoya, C. P. (1989). Cross- 
species responses in the defensive burying paradigm: A comparison between Long-Evans rats (Rattus norvegicus), Richardson's ground squirrels (Spermophilus richardsonii), and thirteen-lined ground squirrels (Catellus tridecemlineatus). Journal of Comparative Psychology, 103, 184-190.

LORE, R., BLANC, A., \& SUEDFELD, P. (1971). Empathic learning of a passive-avoidance response in domesticated Rattus norvegicus. Animal Behaviour, 19, 112-114.

MASON, J. R. (1988). Direct and observational learning by red-winged blackbirds (Agelaius phoeniceus): The importance of complex visual stimuli. In T. R. Zentall \& B. G. Galef, Jr. (Eds.), Social learning: Psychological and biological perspectives (pp. 99-116). Hillsdale, $\mathrm{NJ}$ : Erlbaum

MINEKA, S., \& COOK, M. (1988). Social learning and the acquisition of snake fear in monkeys. In T. R. Zentall \& B. G. Galef, Jr. (Eds.), Social learning: Psychological and biological perspectives (pp. 51-74). Hillsdale, NJ: Erlbaum.

Owings, D. H., \& Coss, R. G. (1977). Snake mobbing by California ground squirrels: Adaptive variation and ontogeny. Behaviour, 62, 50-69.
Pinel, J. P., \& Treit, D. (1978). Burying as a defensive response in rats. Journal of Comparative \& Physiological Psychology, 92, 708-712.

Pinel, J. O. J., TreIT, D., \& WiLkIE, D. M. (1980). Stimulus control of defensive burying in the rat. Learning \& Motivation, 11, 150-163.

TELLE, H. J. (1966). Beitrag zur Kenntnis der Verhaltensweise von Ratten, vergleichand dargestellt bei Rattus norvegicus und Rattus rattus. Zeitschrift für Angewandte Zoologie, 53, 129-196.

TeRKEL, J. (1996). Cultural transmission of feeding behavior in the black rat (Rattus rattus). In C. M. Heyes \& B. G. Galef, Jr. (Eds.), Social learning in animals: The roots of culture (pp. 17-47). San Diego: Academic Press.

Whiten, A., \& HAM, R. (1992). On the nature and evolution of imitation in the animal kingdom: Reappraisal of a century of research. In P. J. B. Slater, J. S. Rosenblatt, C. Beer, \& M. Milinski (Eds.), Advances in the study of behavior (Vol. 21, pp. 239-283). San Diego: Academic Press.

(Manuscript received March 31, 1998; accepted for publication June 25, 1998.) 